\title{
Understanding Weight Loss via Online Discussions: Content Analysis of Reddit Posts Using Topic Modeling and Word Clustering Techniques
}

\author{
Yang Liu ${ }^{1}, \mathrm{MSc}$; Zhijun Yin ${ }^{2,3}, \mathrm{PhD}$ \\ ${ }^{1}$ College of Computer Science and Technology, Changchun Normal University, Changchun, China \\ ${ }^{2}$ Department of Biomedical Informatics, Vanderbilt University Medical Center, Nashville, TN, United States \\ ${ }^{3}$ Department of Electrical Engineering and Computer Science, Vanderbilt University, Nashville, TN, United States
}

Corresponding Author:

Zhijun Yin, PhD

Department of Biomedical Informatics

Vanderbilt University Medical Center

2525 West End Ave.

14th floor, Suite 1475

Nashville, TN, 37023

United States

Phone: 16159363690

Email: zhijun.yin@vanderbilt.edu

\section{Abstract}

Background: Maintaining a healthy weight can reduce the risk of developing many diseases, including type 2 diabetes, hypertension, and certain types of cancers. Online social media platforms are popular among people seeking social support regarding weight loss and sharing their weight loss experiences, which provides opportunities for learning about weight loss behaviors.

Objective: This study aimed to investigate the extent to which the content posted by users in the $r / l o s e i t$ subreddit, an online community for discussing weight loss, and online interactions were associated with their weight loss in terms of the number of replies and votes that these users received.

Methods: All posts that were published before January 2018 in r/loseit were collected. We focused on users who revealed their start weight, current weight, and goal weight and were active in this online community for at least 30 days. A topic modeling technique and a hierarchical clustering algorithm were used to obtain both global topics and local word semantic clusters. Finally, we used a regression model to learn the association between weight loss and topics, word semantic clusters, and online interactions.

Results: Our data comprised 477,904 posts that were published by 7660 users within a span of 7 years. We identified 25 topics, including food and drinks, calories, exercises, family members and friends, and communication. Our results showed that the start weight $(\beta=.823 ; P<.001)$, active days $(\beta=.017 ; P=.009)$, and median number of votes $(\beta=.263 ; P=.02)$, mentions of exercises $(\beta=.145 ; P<.001)$, and nutrition $(\beta=.120 ; P<.001)$ were associated with higher weight loss. Users who lost more weight might be motivated by the negative emotions $(\beta=-.098 ; P<.001)$ that they experienced before starting the journey of weight loss. In contrast, users who mentioned vacations $(\beta=-.108 ; P=.005)$ and payments $(\beta=-.112 ; P=.001)$ tended to experience relatively less weight loss. Mentions of family members $(\beta=-.031 ; P=.03)$ and employment status $(\beta=-.041 ; P=.03)$ were associated with less weight loss as well.

Conclusions: Our study showed that both online interactions and offline activities were associated with weight loss, suggesting that future interventions based on existing online platforms should focus on both aspects. Our findings suggest that online personal health data can be used to learn about health-related behaviors effectively.

(J Med Internet Res 2020;22(6):e13745) doi: 10.2196/13745

\section{KEYWORDS}

weight loss; online health community; machine learning; topic modeling; word2vec; hierarchical clustering; consumer health 


\section{Introduction}

\section{Background}

Maintaining a healthy weight can reduce the risk of developing many diseases, including type 2 diabetes, hypertension, heart disease and strokes, kidney diseases, and certain types of cancers [1-6]. Unfortunately, overweight or obesity has nowadays become a public health crisis that impacts many Americans. For example, it was reported that nearly 94 million US adults were affected by obesity in 2015 and the annual medical cost was approximately US $\$ 150$ billion [7]. To promote public health and help control overweight and obesity, it is critical to understand what factors are associated with weight loss and design effective weight loss interventions.

Over the past decade, people have been increasingly leveraging online social media platforms to share personal experiences and seek social support regarding weight loss, understand the impact of obesity, and learn their interpretation as contributing factors to a healthy life [8]. This huge amount of online information enables health care providers and researchers to gain insights into both public and personal health. For example, studies showed that what people shared on Instagram and Twitter could be used to effectively assess obesity prevalence in the United States $[9,10]$. While a content analysis showed that Twitter users were more likely to discuss weight loss during and after holidays [11], a survey-based study suggested that the interactions on Twitter were too brief and shallow [12], which might constrain its users to gain deep social support. This is, however, a major motivation for people to engage in other online weight loss forums or communities [13].

As such, recent studies, which aimed to prevent obesity and promote healthy weight loss, tended to incorporate online social media platforms into their intervention design, but the effects were found to be mixed. While some investigations showed that these online platforms had the potential for an innovative weight loss intervention [14,15], others found their effects were limited because of a low retention and engagement rate [16,17]. Moreover, a meta-analysis of over 2000 studies concluded that the effects of the interventions incorporating online social networks were very modest in improving health-promoting behaviors [18]. This suggested that before designing interventions based on qualitative evidence that online support and engagement are helpful [19], a quantitative analysis is necessary in determining how online interactions with other users (as a potential external influential factor), and a user's offline activities recorded in online discussions (as a potential internal driving factor), are associated with their weight loss.

\section{Current Research and Its Limitation}

It should be noted that there were studies showing that consistent online activities (eg, updating progress in weight loss and interacting with others) in online weight loss programs or training were associated with higher weight loss [20-22]. Particularly, a study using data from $r$ /loseit showed that higher BMI levels and higher online activities were associated with more weight loss [23]. Similarly, another study based on causal inference found that, on average, users who received comments in $r$ /loseit lost $9 \mathrm{lb}$ more than users who did not receive any comments [24]. Although online interactions were shown to have a significant impact on weight loss [25], existing studies focused less on the content of posts. While both the aforementioned studies used topic modeling to extract topics, they merely focused on the most popular ones. This method, however, was too general to identify detailed offline activities that were disclosed in such a large number of posts. Moreover, these studies used the data that were generated during 2010 and 2014, which, as we showed later, consisted of only a small fraction of the posts published in $r /$ loseit.

In fact, highlighting both online interactions and personal offline activities aligns with social cognitive theory (SCT) [26]. The theory emphasizes that external and internal social reinforcement together lead to behavior change in a dynamic fashion and is often applied to guild the design of effective intervention strategies [27]. This suggests that focusing on either online interactions or personal offline activities but not both might lead to an incomplete view of the roles of online communities in the process of weight loss, but this needs to be examined and confirmed with evidence.

\section{Objective}

Therefore, considering the limitation of previous studies and inspired by SCT, we aimed to investigate the extent to which the offline activities communicated by users in the $r /$ loseit subreddit, an online community for discussing weight loss, and online interactions were associated with their weight loss. Specially, we focused on a data set consisting of 477,904 posts that were published by 7660 users before January 2018 in r/loseit. We used the self-reported weight change to measure weight loss and the average number of comments and votes that they received from other users to characterize online interactions. We applied both topic modeling and word clustering to obtain detailed and interpretable contributing factors from online posts. Finally, we used a linear regression model to quantitively examine the association between online interactions, factors described in online discussions, and the amount of weight loss.

Our work provided evidence that an online social media platform can serve as an effective data source to understand weight loss, and our findings implied that in future weight loss analyses or interventions, online interactions should be considered as a factor that influences long-term self-efficacy.

\section{Methods}

\section{Data}

Our data were collected from $r$ /loseit, a subreddit focusing on weight loss in Reddit, an online discussion platform. Within the subreddit, users can either publish a submission to start a new discussion thread or make comments on either a submission or another comment to an existing discussion thread. For simplicity, we used the word post to denote either a submission or a comment when we did not differentiate them. In addition, Reddit users can upvote or downvote a comment but can only upvote a submission. Furthermore, users in many subreddits are allowed to enter text or symbols into a flare, which appears next to their usernames in a post, to show some basic 
information of themselves. For example, in r/loseit, users can show their start weight, current weight, and goal weight and even their gender, age, and height information in flairs. However, as creating a flare is not required, users can ignore it when publishing a post.

In this study, we used the Python Reddit API Wrapper python package (version 5.3.0) to extract data from the Reddit application programming interface. Specifically, we collected all the posts in $r$ /loseit that were published before January 13, 2018. We used the flares tagged with usernames to confine our study cohorts to those users who disclosed their start, current, and goal weights and were active for at least 30 days in this subreddit [23]. It should be noted that we did not ask for permission to use the data from the Reddit community because the data are publicly accessible. However, we never tried to identify any Reddit user by linking their Reddit data with additional data sets. All the results, and post samples presented in this paper, were carefully examined and revised such that no personally identifiable information was disclosed.

\section{Topic Modeling and Word Semantic Clustering}

Owing to high dimensionality, noise, and ambiguity of natural language text, processing and analyzing raw post content are often challenging, and the analyzed results are difficult to interpret. In this study, we used 2 types of methods to mitigate this problem: topic modeling and word semantic clustering based on low dimensional representation (eg, word2vec) [28]. While topic modeling can help identify themes in a global context, word semantic clusters can provide more detailed concepts in a local context [29].

Specifically, we used the implementation of latent Dirichlet allocation (LDA) in Mallet (version 2.0.8) to identify the main topics of online discussions in r/loseit [30]. Since LDA is an unsupervised algorithm, we relied on a coherence score to determine the optimal number of topics [31]. In this study, we trained LDA models for 5 to 75 topics (with a step size of 5) on all of the posts and chose the number of topics that was corresponding to the highest coherence score. To mitigate word sparsity, we only kept nouns, verbs, adjectives, and adverbs.

To obtain word semantic clusters, we relied on the Google pretrained word2 vec model because our data set was not large enough to train an accurate word2vec model. We relied on the standard deviation of cluster size to determine the optimal number of clusters [29]. Specifically, we used a hierarchical clustering algorithm with 25 to 1000 clusters (with a step size of 25) and used the elbow rule to the standard deviation of the number of words in clusters. Intuitively, a large word cluster is more likely to contain multiple concepts, while a small word cluster is more likely to have little contribution to reducing hundreds of thousands of word dimensions [29].

\section{Regression Analysis}

In this study, we investigated the association between weight loss and online discussions by using a linear regression model. Specifically, we characterized a user's online discussion by using the following predictors:

- The days that the user was active in the subreddit.

- The number of posts that the user published.

- The topics conveyed in the posts, measured by topic distribution.

- The word semantic clusters, measured by term frequency-inverse document frequency values.

- The median karma score or votes that the user received for each post, measured by subtracting the number of upvotes from the number of downvotes [32].

- The median number of comments for each post that the user published.

We used weight loss, measured by subtracting the start weight from the current weight, as the outcome variable of the regression model. As the distribution of the weight loss variable is right-skewed, we log-transformed it before feeding it into the regression model. All the predictors were normalized and scaled into a range of $(0,1)$. It should be noted that the active days and the number of comments were also log-transformed because of their right-skewed distributions.

Considering that a person who had higher weight at the beginning is more likely to lose more weight, we also introduced start weight as a control variable in the model. Before applying the regression analysis, we used the findCorrelation function, as implemented in the caret $\mathrm{R}$ package (version 6.0-81), with a cutoff of 0.3 to remove correlated predictors. We reported predictors with a statistical significance level of .05 .

\section{Results}

\section{Data Statistics}

We collected 2,526,277 posts published by 205,722 users during the period between July 30, 2010, and January 13, 2018. Focusing on the users who disclosed their start, current, and goal weights in flairs, we finally obtained 7660 users with a total of 477,904 posts. These posts included 16,332 submissions and 461,572 comments. Table 1 summarizes the basic statistics of key factors regarding this study cohort. From the table, we observed that most posts received a small number of comments and karma scores.

Figure 1 shows the number of posts for each year during 2010 and 2018. From the figure, we can see that the number of posts surged after 2014. It should be noted that the number of posts in 2018 was small because there were only 2-week data before we stopped data collection. 
Table 1. Basic statistics of the study cohort.

\begin{tabular}{llll}
\hline Statistics & 25th percentile & Median & 75th percentile \\
\hline The number of posts per user, $\mathrm{n}$ & 8 & 19 & 52 \\
The number of words per post, $\mathrm{n}$ & 18 & 220.0 & 265.0 \\
The start weight (lb) & 183.0 & 30.0 & 52.0 \\
Weight loss (lb) & 16.0 & 89 & 281 \\
Active days, $\mathrm{n}$ & 21 & 1 & 1 \\
The number of comments for each post, $\mathrm{n}$ & 1 & 2 & 3 \\
The karma score for each post, $\mathrm{n}$ & 1 & &
\end{tabular}

Figure 1. The number of posts published in this subreddit in each year (from July 30, 2010, to January 13, 2018).

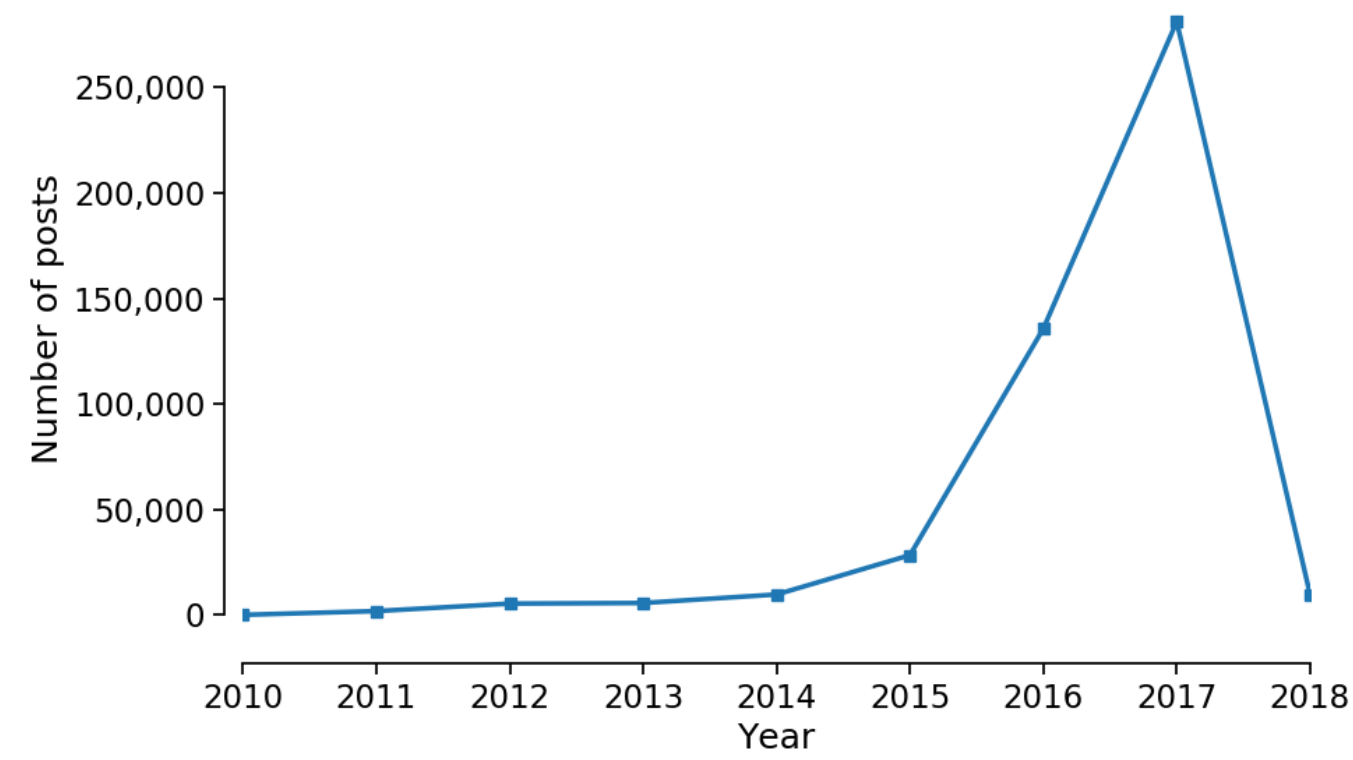

\section{Topics Discovered in Online Discussions}

We identified 25 topics that were corresponding to the highest coherence score (Multimedia Appendix 1). Table 2 shows the inferred topics, their marginal distribution, and the most relevant terms. The marginal distribution of a topic was measured by the probability that the topic was sampled from online discussions, while the relevance of a term was measured by the probability that it was sampled from a topic. The identifier of each topic was named based on the descending order of their topic distribution. For example, topic T1, talking about drinks, had the highest distribution, while topic T25, one of the weight change-related topics, had the lowest topic distribution.

We also manually summarized the 25 topics into 11 categories and provided the associated labels in Table 2. The table shows that people in this subreddit often talked about food and drinks, exercise, calorie, clothes, time, health issues, weight change, feelings, plans, and communication. 
Table 2. The 25 topics that were identified from $\mathrm{r} /$ loseit. The sample terms were ordered based on their relevance to the topic. The distribution of each topic is calculated on all the posts published by these users.

\begin{tabular}{|c|c|c|}
\hline Label and ID & Most relevant terms & Distribution (probability) \\
\hline \multicolumn{3}{|c|}{ Food or drinks } \\
\hline $\mathrm{T} 2$ & water, drink, lot, drinking, make, soda, cut, diet, beer, bit, thing, alcohol & .053 \\
\hline T11 & eat, food, meal, eating, lunch, dinner, hungry, calorie, breakfast, pizza & .051 \\
\hline $\mathrm{T} 21$ & food, diet, eating, eat, low, protein, fat, calorie, lot, high, carbs, cico & .049 \\
\hline $\mathrm{T} 22$ & veggie, chicken, salad, cheese, add, recipe, make, cook, egg, rice, meat & .048 \\
\hline \multicolumn{3}{|l|}{ Health issues } \\
\hline T5 & doctor, body, issue, problem, health, level, pain, energy, effect, surgery & .052 \\
\hline \multicolumn{3}{|c|}{ Family or friends } \\
\hline T6 & friend, family, guy, kid, mom, school, husband, life, live, told, girl & .052 \\
\hline \multicolumn{3}{|l|}{ Calorie } \\
\hline $\mathrm{T} 7$ & calorie, deficit, exercise, tdee, eat, counting, count, eating, daily, mfp & .052 \\
\hline $\mathrm{T} 8$ & calorie, chocolate, sugar, sweet, snack, coffee, craving, bar, fruit, cal, cup & .051 \\
\hline \multicolumn{3}{|l|}{ Exercise } \\
\hline T9 & run, running, walk, minute, time, walking, mile, step, hour, half, long & .051 \\
\hline $\mathrm{T} 16$ & gym, exercise, muscle, workout, start, working, work, body, cardio & .049 \\
\hline \multicolumn{3}{|c|}{ Weight change } \\
\hline $\mathrm{T} 3$ & lb, year, lost, month, started, pound, back, ago, gained, weight, starting & .052 \\
\hline $\mathrm{T} 17$ & weight, lose, loss, fat, body, gain, healthy, bmi, height, normal, range & .049 \\
\hline $\mathrm{T} 25$ & week, scale, weight, pound, number, plateau, drop, weighing, daily & .043 \\
\hline \multicolumn{3}{|l|}{ Feelings } \\
\hline $\mathrm{T} 12$ & thing, work, make, find, lot, time, hard, put, give, won, easy, worry & .051 \\
\hline $\mathrm{T} 13$ & goal, hit, progress, end, picture, feel, close, happy, set, time, challenge & .050 \\
\hline $\mathrm{T} 14$ & feel, feeling, eating, binge, bad, stop, time, control, hard, stress, struggle & .050 \\
\hline \multicolumn{3}{|c|}{ Communication or encouragement } \\
\hline $\mathrm{T} 1$ & good, pretty, yeah, luck, lol, idea, feel, kind, sound, guess, bit, haha, stuff & .053 \\
\hline $\mathrm{T} 10$ & people, person, health, comment, understand, talk, mental, life, care & .051 \\
\hline $\mathrm{T} 23$ & post, read, check, https_www, question, loseit, app, mfp, reddit, http & .048 \\
\hline $\mathrm{T} 24$ & great, love, awesome, job, amazing, congrats, hope, sound, glad, similar & .046 \\
\hline \multicolumn{3}{|c|}{ Plan or decision } \\
\hline $\mathrm{T} 4$ & day, week, back, track, maintenance, couple, plan, log, logging, cheat & .052 \\
\hline $\mathrm{T} 18$ & change, time, make, start, long, life, habit, making, thing, choice, healthy & .049 \\
\hline $\mathrm{T} 20$ & time, thought, made, felt, wanted, started, back, needed, decided, found & .049 \\
\hline \multicolumn{3}{|l|}{ Clothes } \\
\hline T19 & fit, size, clothes, big, wear, buy, pant, bought, short, shirt, dress, store & .049 \\
\hline \multicolumn{3}{|l|}{ Time } \\
\hline $\mathrm{T} 15$ & today, morning, night, yesterday, work, tomorrow, weekend, day, home & .050 \\
\hline
\end{tabular}

\section{Regression Analysis}

We chose 425 as the optimal number of word clusters based on the elbow rule (Multimedia Appendix 1). The word semantic clusters, together with other proposed predictors, were applied to fitting a linear regression model. After examining the feature correlation, we included 6 topics and 402 word semantic clusters into the regression model. Figure 2 shows the distribution of the log-transformed weight loss, which matches the loose constraint of applying a linear regression model. 
Figure 2. Histogram of log-transformed weight loss.

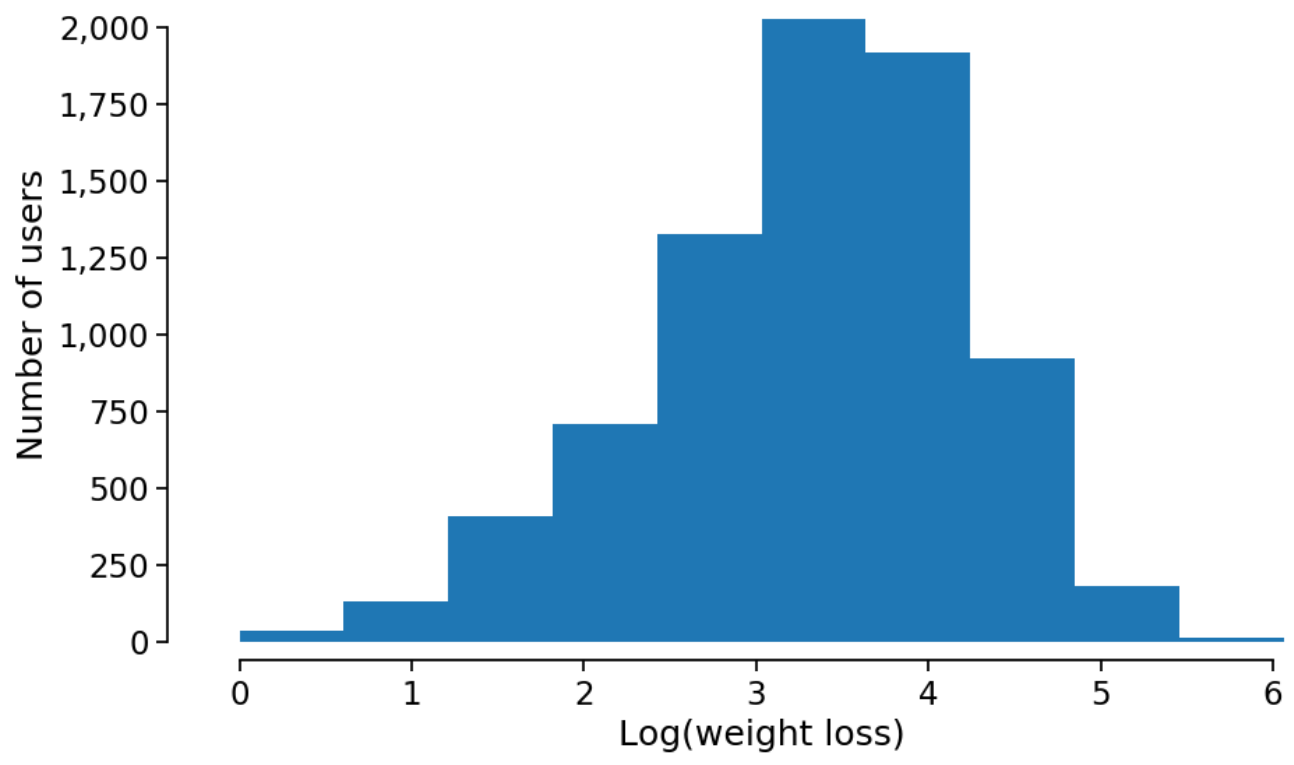

\section{Goodness of Fit and Non-content Predictors}

The fitted linear regression model had an adjusted $R^{2}=0.315$, $F_{7,191}=9.553$, and $P<.001$, suggesting that the model with proposed predictors predicted weight loss better than the basic intercept-only model. Among the non-content-related predictors, the start weight $(\beta=.823 ; P<.001)$, the active days in the subreddit $(\beta=.02 ; P=.009)$, and the median karma score $(\beta=.263$; $P=.02)$ were associated with higher weight loss. However, the median number of comments was not significantly associated with weight loss in our analysis $(\beta=.001 ; P=.95)$.

\section{Topic-Related Predictors}

There were 3 topics that were found to be significantly associated with weight loss. Topics T16 (exercise in the gym) and T19 (purchase of clothes) were associated with higher weight loss ( $\beta=.072 ; P=.007$ and $\beta=.080 ; P<.001$, respectively), while topic T7 (counting calorie) was associated with lower weight loss $(\beta=-.074 ; P=.007)$.

\section{Word Semantic Cluster-Related Predictors}

Table 3 shows word semantic clusters that were significantly associated with higher weight loss, which are summarized below. 
Table 3. Word semantic clusters that were statistically significant with respect to weight loss. Sample words are presented based on their distances to the center of a cluster in ascending order.

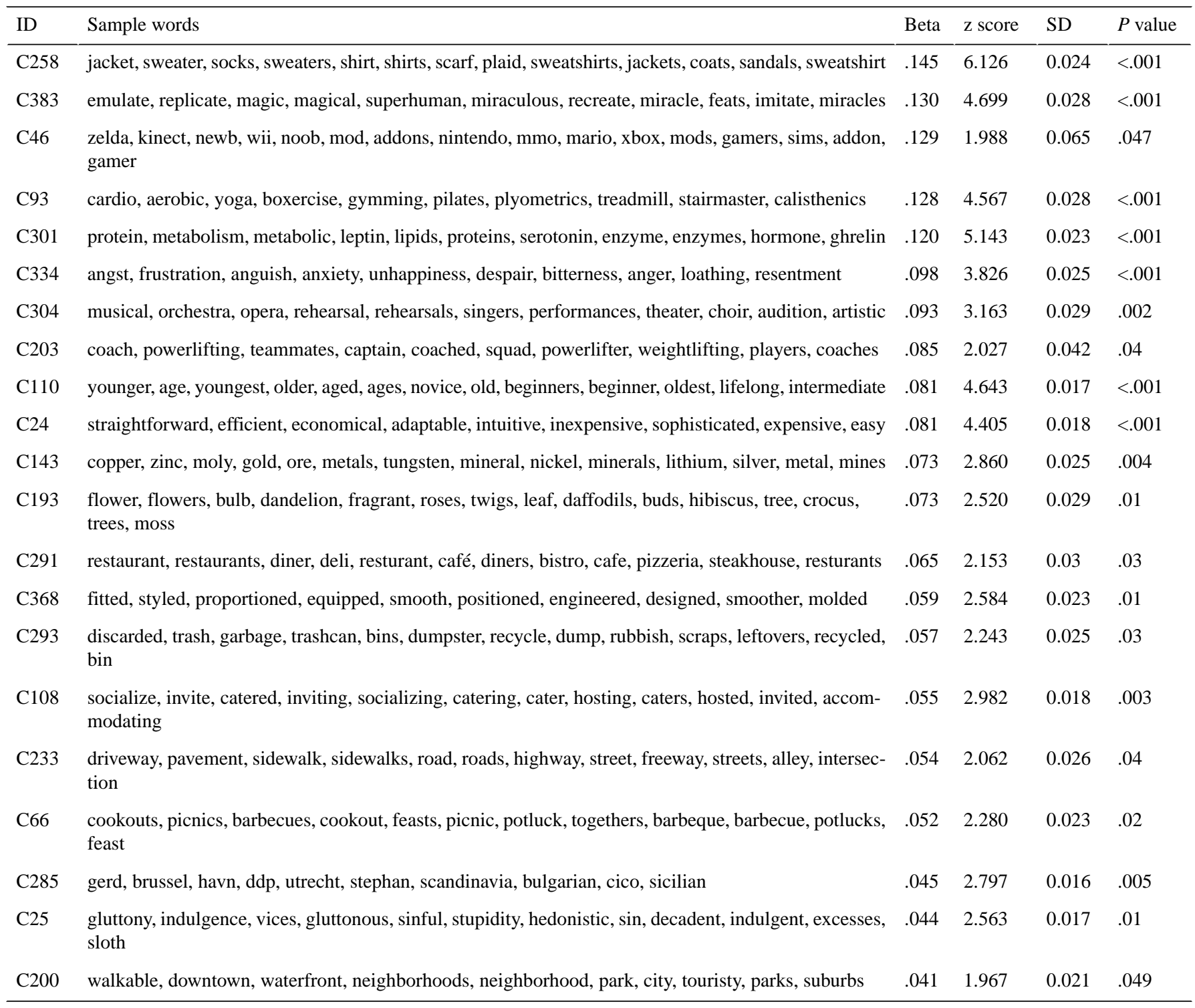

\section{Exercise-Related Clusters}

Exercise-related clusters included C258 (clothes), C46 (Xbox games), C93 (cardio), C203 (coaching), C233 (roads), C285 (city-related food, exercise), and C200 (hangouts places). The following are some examples that were composed by users with higher weight loss:

6 shirts, 2 sweaters, 6 jeans and my belts are on the last hole! I was so surprised when I read a post about new cloths and the belt was mentioned...I never knew I was already on the last hole D: I don't need to use it, but I certainly can!

You forget that with muscles, you'll burn more fat. $80 \%$ of my training consists of strength and I do some small amount of cardio on the side.

I liked the suggestions and coaching from the jawbone app, but the overestimation is why I got a Fitbit with a heart rate monitor.

\section{Diet- or Dining-Related Clusters}

Diet- or dining-related clusters included C301 (nutrition), C143 (minerals), C291 (restaurant), C293 (leftover), C108 (hosting), C66 (cookout), C25 (evil gluttony), and C285 (city-related food, exercise). The following are some examples that were communicated in related posts:

today I eat a pancake with plain greek yoghurt as a pre-workout in-work snack, after gym I will inhale two greek yoghurts with two spoons of protein powder, which catapults me to $170 \mathrm{~g}$ of protein today. I think I've spent more time replacing bad items (like I have asparagus and Brussel sprouts instead of freezer fries now, for example) with better options than I have really giving things up.

I learned the same thing with pizza. I love pizza, but nowadays I would much rather enjoy a slice of pizza from a good local restaurant, than an entire pizza from Domino's or Papa John's. 
And knowing myself before I started losing weight, if I can do it so can everyone else. I was the embodiment of laziness, gluttony and excuses.

\section{Other Clusters}

Other clusters included C304 (performances), C334 (negative emotions), C24 (simple, straightforward, economic), C193 (flowers), C110 (beginner), and C383 (replicate). The following are some examples of these clusters:

I ended up just drinking water at the theater because everything was either full of calories or full of sugar. ended up having some leftover chicken and a banana when I got home.

About the anxiety, yea same boat. I struggle with social anxiety since I'm 13 years old but it did get a lot better over the last few months.
Look into a Hot Pot-they are relatively inexpensive $(<\$ 15)$ and at least allow you to do some basics like cook rice/pasta/soup/sauces.

Finished the 13-week beginner program on DDP Yoga. Hit every workout on the schedule, didn't lag behind the schedule by even a single day once...Feels great to have stuck with it so well.

I got flowers at work! And a sweet little card that said "I'm proud of you" from my mom because of how much effort and progress I've made in the last two months.

Table 4 shows word semantic clusters that were significantly associated with lower weight loss, which are summarized below. 
Table 4. Word semantic clusters that were statistically significant with respect to weight loss. Sample words are presented based on their distances to the center of a cluster in ascending order.

\begin{tabular}{|c|c|c|c|c|c|}
\hline ID & Sample words & Beta & z score & SD & $P$ value \\
\hline C153 & rising, dwindle, skyrocket, soar, rise, skyrockets, fluctuating, rises, fluctuates, spiking, spike, fluctuate & -.148 & -2.782 & 0.053 & .005 \\
\hline C359 & $\begin{array}{l}\text { purple, blue, colored, pink, brown, orange, burgundy, red, teal, gray, yellow, russet, tangerine, shades, } \\
\text { amber }\end{array}$ & -.125 & -3.464 & 0.036 & .001 \\
\hline $\mathrm{C} 120$ & request, permission, allotted, permit, requesting, requested, requests, alloted, permits, allotment, orders & -.114 & -2.283 & 0.05 & .02 \\
\hline C266 & $\begin{array}{l}\text { payments, payment, allowances, reimbursement, deduct, refund, deduction, benefits, premiums, } \\
\text { payout }\end{array}$ & -.112 & -3.282 & 0.034 & .001 \\
\hline C184 & $\begin{array}{l}\text { vacation, vacations, getaway, vacay, resort, vacationing, resorts, honeymoon, hassle, hotels, hotel, } \\
\text { disneyworld }\end{array}$ & -.108 & -2.821 & 0.038 & .005 \\
\hline $\mathrm{C} 262$ & $\begin{array}{l}\text { measurements, measurement, measuring, correlate, tracking, analysis, quantifying, monitoring, } \\
\text { mapping }\end{array}$ & -.108 & -3.627 & 0.030 & $<.001$ \\
\hline $\mathrm{C} 80$ & $\begin{array}{l}\text { downstairs, sofa, upstairs, hallway, doorway, drawers, room, couch, cupboards, stairwell, bookshelf, } \\
\text { fireplace }\end{array}$ & -.107 & -2.022 & 0.053 & .04 \\
\hline $\mathrm{C} 418$ & $\begin{array}{l}\text { hotline, contacting, contact, dialing, dialed, emailing, dial, calling, information, calls, info, referrals, } \\
\text { referral }\end{array}$ & -.105 & -5.653 & 0.019 & $<.001$ \\
\hline C263 & $\begin{array}{l}\text { convince, persuade, entice, woo, coax, appease, tempt, lure, excite, inspire, convey, enlighten, quell, } \\
\text { quench }\end{array}$ & -.101 & -4.830 & 0.021 & $<.001$ \\
\hline $\mathrm{C} 421$ & production, producers, manufacturers, producing, output, prices, price, produce, pricing, manufacturer & -.091 & -2.618 & 0.035 & .009 \\
\hline C375 & skinny, chubby, endomorph, lithe, pudgy, muscly, muscley, beefy, chunky, muscular, scrawny, lanky & -.084 & -2.552 & 0.033 & .01 \\
\hline C395 & alternative, viable, workable, safe, safer, safest, alternatives, foolproof, alternate, bulletproof, inclusive & -.083 & -3.455 & 0.024 & .001 \\
\hline C103 & $\begin{array}{l}\text { tools, design, recommendations, recommended, designing, advice, recommend, materials, designs, } \\
\text { kits }\end{array}$ & -.082 & -3.075 & 0.027 & .002 \\
\hline $\mathrm{C} 20$ & $\begin{array}{l}\text { split, dividing, separate, separating, splitting, divides, separated, divided, splits, divide, seperate, } \\
\text { separation }\end{array}$ & -.070 & -3.867 & 0.018 & $<.001$ \\
\hline $\mathrm{C} 227$ & league, scouts, rookie, leagues, teams, club, clubs, scout, seasons, season, veteran, rounder, draft & -.069 & -2.911 & 0.024 & .004 \\
\hline C142 & $\begin{array}{l}\text { budge, averse, succeeded, budging, budged, backslid, waver, incapable, qualms, bother, regressed, } \\
\text { headway }\end{array}$ & -.062 & -2.756 & 0.023 & .006 \\
\hline C51 & $\begin{array}{l}\text { asda, morrisons, waitrose, sainsbury, sainsburys, weightwatchers, lidl, quorn, crisps, weetabix, } \\
\text { twinings }\end{array}$ & -.060 & -2.642 & 0.023 & .008 \\
\hline C363 & tonsils, cavities, tooth, pimples, molar, redness, toenails, teeth, sinuses, jaw, bone, zits, sinus, pimple & -.058 & -2.232 & 0.026 & .03 \\
\hline $\mathrm{C} 18$ & $\begin{array}{l}\text { varying, variety, varied, various, differing, different, multiple, individual, diverse, longevity, effec- } \\
\text { tiveness }\end{array}$ & -.056 & -3.412 & 0.016 & .001 \\
\hline $\mathrm{C} 124$ & $\begin{array}{l}\text { undergraduate, college, undergrad, graduate, university, semester, graduates, semesters, academic, } \\
\text { colleges }\end{array}$ & -.055 & -2.117 & 0.026 & .03 \\
\hline C92 & maintenance, maintanence, maintence, maintenace, repairs, maintenence, maintainance, maintainence & -.050 & -2.207 & 0.023 & .03 \\
\hline C229 & tweak, tweaking, tweaked, adjust, revising, updating, modifying, tweaks, modify, adjusting, readjust & -.046 & -2.228 & 0.021 & .03 \\
\hline C17 & employed, working, work, volunteer, volunteering, volunteered, engaged, worked, engage, hire, hired & -.041 & -2.127 & 0.019 & .03 \\
\hline C333 & $\begin{array}{l}\text { moisturizer, lotion, creams, moisturizers, moisturizing, lotions, shampoo, cleanser, exfoliating, } \\
\text { moisturising }\end{array}$ & -.034 & -2.228 & 0.015 & .03 \\
\hline C239 & $\begin{array}{l}\text { mother, daughter, aunt, niece, son, dad, grandmother, father, cousin, uncle, husband, wife, brother, } \\
\text { sister }\end{array}$ & -.031 & -2.133 & 0.014 & .03 \\
\hline
\end{tabular}

\section{Activity-Related Clusters}

Activity-related clusters included C184 (vacation), C227 (clubs, scouts), C124 (college, graduation), C92 (maintenance), and C17 (employment, volunteer). The following are some examples that were posted by users with lower weight loss:

I was fortunate enough to go on 2 European vacations this year (Italy in April, France and London 2 weeks ago) and I've gained 10lbs on top of the 15 I was already planning on losing.

At my thinnest after college I was 5'6" $165 \mathrm{lbs}$, and after I put 20 or 30 lbs back on my mom said she was relieved because I was starting to look "too thin."

I'm actively seeking employment, so it depends what time I wake up if I have breakfast or not, but my usual day consists of... 
My weekend was okay. Had a big unhealthy meal yesterday but stayed $200 \mathrm{cal}$. under maintenance.

\section{Verb and Adjective Clusters}

Verb and adjective clusters included C153 (skyrocket), C120 (request), C418 (contact hotline), C263 (entice related words), C20 (separate), C142 (backtrack), C229 (readjust), C359 (color), C375 (chunky), and C18 (various). The following are some examples:
I'm already exercising an hour 6 days a week. I really can't push it any more than that because my appetite skyrockets.
I have three diagnosed illnesses and have been hospitalized twice. Users who exhibit suicidal behavior should be pointed to suicide prevention hotlines..
I've backtracked by a couple weeks, which is partially water weight, and partially actual weight gain. It sucks.
However, I'm over my 1200 for the day, not by much but I made a silly calorie budgeting decision earlier in the day. I readjusted dinner to try to make up for it, but I was too far in the hole.
I was a chubby child, a chubby adult, and I've NEVER been in an acceptable BMI zone.

\section{Expense-Related Clusters}

Expense-related clusters included C226 (payment, refund), C80 (home design), C51 (supermarket), C363 (otolaryngology related issues), C421 (production, price), C333 (moisturizer), and C239 (family members). The following are some examples that were related to these clusters:

I haven't been to the gym in over a week, and honestly don't think I will unless I can come up with $\$ 350$ for the remainder of my Personal Training payments...oh, and more money for actual membership dues.

I have enough motivation to get myself to the gym and am actually starting to have fun, but today I went after 4 weeks of not going, because I had my tonsils removed.

Guilty of this! I tend to drink more frequently than my husband. I was going to try to stop drinking on weekdays. However last week, for whatever reason, he had a beer $4 / 7$ nights.

\section{Discussion}

\section{Principal Findings}

We used topic modeling to identify 25 general topics from the $r /$ loseit subreddit. These topics covered a broad range of weight loss-related themes, including food and drinks, exercises, calorie, health issues, family members and friends, feelings, and communication. Among these topics, topics regarding food and drinks, health issues, family members and friends, calorie, and exercise were most discussed. These topics were aligned with the findings from another study [23].
Our regression analysis showed that the start weight and active days were associated with higher weight loss, which was aligned with our common sense. Furthermore, our results showed that receiving a higher karma score was associated with higher weight loss, but the median number of comments received was not significantly associated with weight loss. Our findings were a little different from the two studies, where both the karma score and comments were associated with higher weight loss $[24,25]$. We suspected that this might be because (1) we included far more users in our study and most of the posts received a very limited number of comments (Table 1) and (2) the previous studies did not control the model with more detailed content.

After adjusting for active days, start weight, karma score, and the median number of comments received, our analysis suggested that exercises, including coaching and nutrition, were the most effective content factors that were associated with higher weight loss, which were confirmed by previous investigations [33,34]. In addition, users with higher weight loss mentioned negative emotions that they experienced before they started to make efforts for weight loss. Our findings also suggested that mentioning food-related topics (eg, not eating too much, eating healthy food) were associated with higher weight loss, which was also found in a previous study [35]. Interestingly, we found that the mention of Xbox games was associated with higher weight loss as well. Evidence suggested that incorporating active video games had a positive effect on increasing physical activity and promoting healthy weight for both overweight adults and children [36,37].

In addition, we found that many content factors were associated with lower weight loss. For example, we found that people who mentioned vacations and clubs were more likely to have lower weight loss [38]. Furthermore, users in this subreddit mentioned that they gained weight after college graduation. Those users who had lower weight loss often mentioned supermarkets, payment or refund to exercise programs, and employment $[39,40]$. We also found that users who experienced health issues related to otolaryngology tended to have less weight loss. This might be due to the fact that the related treatment disturbed the weight loss plan. However, a study found that otorhinolaryngologic diseases themselves were associated with patients with obesity [41].

Another interesting finding was that users who used skyrocket to describe their weight loss experience (eg, feeling of eating) were less likely to have significant weight loss. This suggested that controlling the diet extensively during this process might not be an effective, healthy strategy [42]. In addition, users who often mentioned maintenance (eg, maintaining the intake of calories) were less likely to lose weight as expected. After a close examination of the related posts, we found that some of these users struggled with weight loss activities. We also found that expense-related content was associated with lower weight loss. This could be explained by a recent finding that low socioeconomic status was associated with lower weight loss outcomes [43]. Finally, users who mentioned family members were found less likely to lose more weight, suggesting that family members may not always have a positive impact on weight loss as found by other studies [44]. 
It should be noted that after examining feature correlation, only 6 topic predictors were included in the regression model, suggesting that word semantic clusters can capture more detailed offline activities. It was interesting that we found a calorie-related topic (T7) associated with lower weight loss, which could be partially supported by a previous finding that reducing calorie intake alone may not help in weight loss [45].

\section{Implications}

In this study, we acknowledged that while some associations were statistically significant, the value of the coefficients was very low, indicating a weak correlation between predictors and the dependent variable. However, we did not directly interpret the predictor importance from the values of their coefficients. This is because it is practically meaningless to say that more weight can be reduced by increasing the distribution of a certain topic discussed in an online community [46]. Rather, we believe that it is the actual offline activities described in online discussions (or self-efficacy) that actually matter in weight loss. By using word clusters, we obtained more detailed, concrete offline activities that were often ignored by other social media-based studies but were significantly associated with the amount of weight loss. While karma scores (votes) from other users were associated with higher weight loss, considering the right-skewed distribution of karma scores (Table 1 and Multimedia Appendix 1), a majority of posts in this online community received very small karma scores.

These were somewhat aligned with the findings in an offline, SCT-based weight loss intervention program [47], where self-efficacy and intention, instead of online interaction, were found to be significant factors leading to weight loss. While self-efficacy performed well in weight loss interventions [48-50], there was evidence that self-efficacy may face the challenge of decreasing over time [51]. This is very interesting because it implied that interactions, either in online or offline environments, may serve as an indirect factor that affects weight loss through maintaining a participant's long-term self-efficacy.

From this perspective, future weight loss analyses or interventions should consider online interaction as a key factor to improve self-efficacy, instead of directly being linked to weight loss. Our study also implied that an aggressive weight loss plan may not work in the long run.

\section{Limitations and Future Work}

There are several limitations that we want to highlight here. First, our findings were based on merely the r/loseit subreddit, which constrained the generality of findings. Future work may consider extending the research to other online platforms. Second, we did not incorporate gender into the analysis. It might be possible to first infer such information from online discussions [52] and then investigate how the association between posting content and weight loss changes after controlling for this information. Third, we relied on self-reported weight loss in this study, which limited our investigation, and findings were applicable to only a small fraction of Reddit users who disclosed weight change. It will be interesting to investigate the specific characteristics that are related to the majority of Reddit users who did not report such information. Furthermore, self-reported weight changes might not be accurate because Reddit users might not update their weights in a timely manner. Our study only investigated what was presented in the online discussions, instead of examining the real-world events. Finally, it would be interesting to investigate the extent to which online interaction, not merely responses and votes but the detailed categories, and offline activities that were recorded in online discussions can lead to weight loss change in a dynamic setting.

\section{Conclusions}

In this study, we analyzed online discussions regarding weight loss in r/loseit. We used topic modeling and the hierarchical clustering algorithm to extract topics and word clusters that were discussed in this subreddit. We used a regression analysis to determine the association between weight loss change and the factors that were conveyed in these online discussions. We found that the start weight and median karma scores were associated with higher weight loss. Users who had higher weight loss might be motivated by negative emotions experienced before starting weight loss. By contrast, users who mentioned vacations and payments were less likely to lose more weight. Furthermore, mentions of family members and employment were also found to be associated with lower weight loss. Our findings suggest that future interventions based on online social media platforms should focus on both online interaction and offline activities and that online personal health data can be effectively used to learn about users' health-related behaviors.

\section{Acknowledgments}

The authors thank the colleagues in Changchun Normal University and Vanderbilt University for the positive feedback on this project. Special thanks go to Na Liu from Georgia Institute of Technology for the constructive discussion on the work implication.

\section{Authors' Contributions}

ZY proposed the research question and designed the experiments. YL collected data and conducted the experiments. ZY and YL wrote the manuscript. ZY reviewed the final manuscript.

\section{Conflicts of Interest}

None declared.

\section{Multimedia Appendix 1}

Supplemental materials for selection of the optimal number of topics and the distribution of karma score. 
[DOCX File, 713 KB-Multimedia Appendix 1]

\section{References}

1. Buchwald H, Estok R, Fahrbach K, Banel D, Jensen MD, Pories WJ, et al. Weight and type 2 diabetes after bariatric surgery: systematic review and meta-analysis. Am J Med 2009 Mar;122(3):248-56.e5. [doi: 10.1016/j.amjmed.2008.09.041] [Medline: $\underline{19272486}$ ]

2. Parker ED, Sinaiko AR, Kharbanda EO, Margolis KL, Daley MF, Trower NK, et al. Change in weight status and development of hypertension. Pediatrics 2016 Mar;137(3):e20151662 [FREE Full text] [doi: 10.1542/peds.2015-1662] [Medline: 26908707]

3. Chlebowski RT, Luo J, Anderson GL, Barrington W, Reding K, Simon MS, et al. Weight loss and breast cancer incidence in postmenopausal women. Cancer 2019 Jan 15;125(2):205-212 [FREE Full text] [doi: 10.1002/cncr.31687] [Medline: 30294816]

4. Kovesdy CP, Furth SL, Zoccali C, World Kidney Day Steering Committee. Obesity and kidney disease: hidden consequences of the epidemic. Nephron 2017;135(4):243-251. [doi: 10.1159/000455698] [Medline: 28171864]

5. Stampfer MJ, Hu FB, Manson JE, Rimm EB, Willett WC. Primary prevention of coronary heart disease in women through diet and lifestyle. N Engl J Med 2000 Jul 6;343(1):16-22. [doi: 10.1056/NEJM200007063430103] [Medline: 10882764]

6. Chiuve SE, Rexrode KM, Spiegelman D, Logroscino G, Manson JE, Rimm EB. Primary prevention of stroke by healthy lifestyle. Circulation 2008 Aug 26;118(9):947-954 [FREE Full text] [doi: 10.1161/CIRCULATIONAHA.108.781062] [Medline: 18697819]

7. Centers for Disease Control and Prevention. 2019. Adult Obesity Facts URL: https://www.cdc.gov/obesity/data/adult.html [accessed 2019-12-21]

8. Yin Z, Fabbri D, Rosenbloom ST, Malin B. A scalable framework to detect personal health mentions on Twitter. J Med Internet Res 2015 Jun 5;17(6):e138 [FREE Full text] [doi: 10.2196/jmir.4305] [Medline: 26048075]

9. Mejova Y, Haddadi H, Noulas A. \#FoodPorn: Obesity Patterns in Culinary Interactions. In: Proceedings of the 5th International Conference on Digital Health. 2015 Presented at: DH'15; May 18 - 20, 2015; Florence, Italy p. 51-58. [doi: $10.1145 / 2750511.2750524]$

10. Cesare N, Dwivedi P, Nguyen QC, Nsoesie EO. Use of social media, search queries, and demographic data to assess obesity prevalence in the United States. Palgrave Commun 2019 Sep 17;5(106):1-9. [doi: 10.1057/s41599-019-0314-x]

11. Turner-McGrievy GM, Beets MW. Tweet for health: using an online social network to examine temporal trends in weight loss-related posts. Transl Behav Med 2015 Jun;5(2):160-166 [FREE Full text] [doi: 10.1007/s13142-015-0308-1] [Medline: 26029278]

12. Pagoto S, Schneider KL, Evans M, Waring ME, Appelhans B, Busch AM, et al. Tweeting it off: characteristics of adults who tweet about a weight loss attempt. J Am Med Inform Assoc 2014;21(6):1032-1037 [FREE Full text] [doi: 10.1136/amiajnl-2014-002652] [Medline: 24928175]

13. Reading JM, Buhr KJ, Stuckey HL. Social experiences of adults using online support forums to lose weight: a qualitative content analysis. Health Educ Behav 2019 Dec;46(2_suppl):129-133. [doi: 10.1177/1090198119859403] [Medline: 31742458]

14. Napolitano MA, Hayes S, Bennett GG, Ives AK, Foster GD. Using Facebook and text messaging to deliver a weight loss program to college students. Obesity (Silver Spring) 2013 Jan;21(1):25-31 [FREE Full text] [doi: 10.1002/oby.20232] [Medline: 23505165]

15. Merchant G, Weibel N, Patrick K, Fowler JH, Norman GJ, Gupta A, et al. Click 'like' to change your behavior: a mixed methods study of college students' exposure to and engagement with Facebook content designed for weight loss. J Med Internet Res 2014 Jun 24;16(6):e158 [FREE Full text] [doi: 10.2196/jmir.3267] [Medline: 24964294]

16. Cavallo DN, Tate DF, Ries AV, Brown JD, DeVellis RF, Ammerman AS. A social media-based physical activity intervention: a randomized controlled trial. Am J Prev Med 2012 Nov;43(5):527-532 [FREE Full text] [doi: 10.1016/j.amepre.2012.07.019] [Medline: 23079176]

17. Hales SB, Davidson C, Turner-McGrievy GM. Varying social media post types differentially impacts engagement in a behavioral weight loss intervention. Transl Behav Med 2014 Dec;4(4):355-362 [FREE Full text] [doi: 10.1007/s13142-014-0274-z] [Medline: 25584084]

18. Maher CA, Lewis LK, Ferrar K, Marshall S, de Bourdeaudhuij I, Vandelanotte C. Are health behavior change interventions that use online social networks effective? A systematic review. J Med Internet Res 2014 Feb 14;16(2):e40 [REE Full text] [doi: 10.2196/jmir.2952] [Medline: 24550083]

19. Hagger MS, Weed M. DEBATE: Do interventions based on behavioral theory work in the real world? Int J Behav Nutr Phys Act 2019 Apr 25;16(1):36 [FREE Full text] [doi: 10.1186/s12966-019-0795-4] [Medline: $\underline{31023328]}$

20. Hwang KO, Ning J, Trickey AW, Sciamanna CN. Website usage and weight loss in a free commercial online weight loss program: retrospective cohort study. J Med Internet Res 2013 Jan 15;15(1):e11 [FREE Full text] [doi: 10.2196/jmir.2195] [Medline: 23322819] 
21. Funk KL, Stevens VJ, Appel LJ, Bauck A, Brantley PJ, Champagne CM, et al. Associations of internet website use with weight change in a long-term weight loss maintenance program. J Med Internet Res 2010 Jul 27;12(3):e29 [FREE Full text] [doi: 10.2196/jmir.1504] [Medline: 20663751]

22. Brindal E, Freyne J, Saunders I, Berkovsky S, Smith G, Noakes M. Features predicting weight loss in overweight or obese participants in a web-based intervention: randomized trial. J Med Internet Res 2012 Dec 12;14(6):e173 [FREE Full text] [doi: 10.2196/jmir.2156] [Medline: 23234759]

23. Pappa GL, Cunha TO, Bicalho PV, Ribeiro A, Silva AP, Meira W, et al. Factors associated with weight change in online weight management communities: a case study in the loseit reddit community. J Med Internet Res 2017 Jan 16;19(1):e17 [FREE Full text] [doi: 10.2196/jmir.5816] [Medline: 28093378]

24. Cunha T, Weber I, Pappa G. A Warm Welcome Matters!: The Link Between Social Feedback and Weight Loss in /r/loseit. In: Proceedings of the 26th International Conference on World Wide Web Companion. 2017 Presented at: WWW'17 Companion; April 3 - 7, 2017; Perth, Australia p. 1063-1072. [doi: 10.1145/3041021.3055131]

25. Cunha TO, Weber I, Haddadi H, Pappa GL. The Effect of Social Feedback in a Reddit Weight Loss Community. In: Proceedings of the 6th International Conference on Digital Health Conference. 2016 Presented at: DH'16; April 11 - 13, 2016; Québec, Montréal, Canada p. 99-103. [doi: 10.1145/2896338.2897732]

26. Bandura A. Human agency in social cognitive theory. Am Psychol 1989 Sep;44(9):1175-1184. [doi: 10.1037/0003-066x.44.9.1175] [Medline: 2782727]

27. Shamizadeh T, Jahangiry L, Sarbakhsh P, Ponnet K. Social cognitive theory-based intervention to promote physical activity among prediabetic rural people: a cluster randomized controlled trial. Trials 2019 Feb 4;20(1):98 [FREE Full text] [doi: 10.1186/s13063-019-3220-z] [Medline: $\underline{\text { 30717779] }}$

28. Mikolov T, Sutskever I, Chen K, Corrado G, Dean J. Distributed Representations of Words and Phrases and Their Compositionality. In: Proceedings of the 26th International Conference on Neural Information Processing Systems - Volume 2. 2013 Presented at: NIPS'13; December 5-10, 2013; Lake Tahoe p. 3111-3119 URL: http://dl.acm.org/citation. $\underline{\mathrm{cfm} ? \mathrm{id}=2999792.2999959}$

29. Yin Z, Harrell M, Warner JL, Chen Q, Fabbri D, Malin BA. The therapy is making me sick: how online portal communications between breast cancer patients and physicians indicate medication discontinuation. J Am Med Inform Assoc 2018 Nov 1;25(11):1444-1451. [doi: 10.1093/jamia/ocy118] [Medline: 30380083]

30. Blei DM, Ng AY, Jordan MI. Latent dirichlet allocation. J Mach Learn Res 2003;3:993-1022 [FREE Full text]

31. Stevens K, Kegelmeyer P, Andrzejewski D, Buttler D. Exploring Topic Coherence Over Many Models and Many Topics. In: Proceedings of the 2012 Joint Conference on Empirical Methods in Natural Language Processing and Computational Natural Language Learning. 2012 Presented at: EMNLP-CoNLL'12; July 12-14, 2012; Jeju Island, Korea p. 952-961 URL: https://dl.acm.org/doi/10.5555/2390948.2391052

32. De Choudhury M, De S. Mental Health Discourse on Redditlf- Self Disclosure, Social Support, and Anonymity. In: Association for the Advancement of Artificial Intelligence!. 2014 May 16 Presented at: ICWSM'14; June 1-4, 2014; Ann Arbor, Michigan, USA p. 71-80 URL: https://www.aaai.org/ocs/index.php/ICWSM/ICWSM14/paper/view/8075

33. Foster-Schubert KE, Alfano CM, Duggan CR, Xiao L, Campbell KL, Kong A, et al. Effect of diet and exercise, alone or combined, on weight and body composition in overweight-to-obese postmenopausal women. Obesity (Silver Spring) 2012 Aug;20(8):1628-1638 [FREE Full text] [doi: 10.1038/oby.2011.76] [Medline: 21494229]

34. Painter SL, Ahmed R, Kushner RF, Hill JO, Lindquist R, Brunning S, et al. Expert coaching in weight loss: retrospective analysis. J Med Internet Res 2018 Mar 13;20(3):e92 [FREE Full text] [doi: 10.2196/jmir.9738] [Medline: 29535082]

35. Soeliman FA, Azadbakht L. Weight loss maintenance: A review on dietary related strategies. J Res Med Sci 2014 Mar;19(3):268-275 [FREE Full text] [Medline: 24949037]

36. Trost SG, Sundal D, Foster GD, Lent MR, Vojta D. Effects of a pediatric weight management program with and without active video games a randomized trial. JAMA Pediatr 2014 May;168(5):407-413. [doi: 10.1001/jamapediatrics.2013.3436] [Medline: 24589566]

37. Staiano AE, Abraham AA, Calvert SL. The Wii Club: Gaming for weight loss in overweight and obese youth. Games Health J 2012 Oct 5;1(5):377-380 [FREE Full text] [doi: 10.1089/g4h.2012.0052] [Medline: 23565349]

38. Díaz-Zavala RG, Castro-Cantú MF, Valencia ME, Álvarez-Hernández G, Haby MM, Esparza-Romero J. Effect of the holiday season on weight gain: a narrative review. J Obes 2017;2017:2085136 [FREE Full text] [doi: 10.1155/2017/2085136] [Medline: 28744374]

39. Mutsaerts MA, Kuchenbecker WK, Mol BW, Land JA, Hoek A. Dropout is a problem in lifestyle intervention programs for overweight and obese infertile women: a systematic review. Hum Reprod 2013 Apr;28(4):979-986. [doi: 10.1093/humrep/det026] [Medline: 23427235]

40. Lemstra M, Bird Y, Nwankwo C, Rogers M, Moraros J. Weight loss intervention adherence and factors promoting adherence: a meta-analysis. Patient Prefer Adherence 2016;10:1547-1559 [FREE Full text] [doi: 10.2147/PPA.S103649] [Medline: $\underline{27574404]}$

41. Kim TH, Kang HM, Oh I, Yeo SG. Relationship between otorhinolaryngologic diseases and obesity. Clin Exp Otorhinolaryngol 2015 Sep;8(3):194-197 [FREE Full text] [doi: 10.3342/ceo.2015.8.3.194] [Medline: 26330910] 
42. Institute of Medicine, Food and Nutrition Board, Committee on Military Nutrition Research, Subcommittee on Military Weight Management. Weight Management: State of the Science and Opportunities for Military Programs. Washington, DC: National Academies Press; 2004.

43. Carden A, Blum K, Arbaugh CJ, Trickey A, Eisenberg D. Low socioeconomic status is associated with lower weight-loss outcomes 10-years after Roux-en-Y gastric bypass. Surg Endosc 2019 Feb;33(2):454-459. [doi: 10.1007/s00464-018-6318-6] [Medline: 29987570]

44. Wang ML, Pbert L, Lemon SC. Influence of family, friend and coworker social support and social undermining on weight gain prevention among adults. Obesity (Silver Spring) 2014 Sep;22(9):1973-1980 [FREE Full text] [doi: 10.1002/oby.20814] [Medline: 24942930]

45. Benton D, Young HA. Reducing calorie intake may not help you lose body weight. Perspect Psychol Sci 2017 Sep;12(5):703-714 [FREE Full text] [doi: 10.1177/1745691617690878] [Medline: 28657838]

46. Yin Z, Sulieman L, Malin B. A systematic literature review of machine learning in online personal health data. J Am Med Inform Assoc 2019 Jun 1;26(6):561-576. [doi: 10.1093/jamia/ocz009] [Medline: 30908576]

47. Young MD, Plotnikoff RC, Collins CE, Callister R, Morgan PJ. A test of social cognitive theory to explain men's physical activity during a gender-tailored weight loss program. Am J Mens Health 2016 Nov;10(6):NP176-NP187. [doi: 10.1177/1557988315600063] [Medline: 26275722]

48. Painter SL, Ahmed R, Hill JO, Kushner RF, Lindquist R, Brunning S, et al. What matters in weight loss? an in-depth analysis of self-monitoring. J Med Internet Res 2017 May 12;19(5):e160 [FREE Full text] [doi: 10.2196/jmir.7457] [Medline: 28500022]

49. Brawley L, Rejeski WJ, Gaukstern JE, Ambrosius WT. Social cognitive changes following weight loss and physical activity interventions in obese, older adults in poor cardiovascular health. Ann Behav Med 2012 Dec;44(3):353-364 [FREE Full text] [doi: 10.1007/s12160-012-9390-5] [Medline: 22773225]

50. Nezami BT, Lang W, Jakicic JM, Davis KK, Polzien K, Rickman AD, et al. The effect of self-efficacy on behavior and weight in a behavioral weight-loss intervention. Health Psychol 2016 May 16:- [Epub ahead of print] [FREE Full text] [doi: 10.1037/hea0000378] [Medline: 27183306]

51. McAuley E, Mailey EL, Mullen SP, Szabo AN, Wójcicki TR, White SM, et al. Growth trajectories of exercise self-efficacy in older adults: influence of measures and initial status. Health Psychol 2011 Jan;30(1):75-83 [FREE Full text] [doi: 10.1037/a0021567] [Medline: 21038962]

52. Schwartz HA, Eichstaedt JC, Kern ML, Dziurzynski L, Ramones SM, Agrawal M, et al. Personality, gender, and age in the language of social media: the open-vocabulary approach. PLoS One 2013;8(9):e73791 [FREE Full text] [doi: 10.1371/journal.pone.0073791] [Medline: 24086296]

\section{Abbreviations \\ LDA: latent Dirichlet allocation \\ SCT: social cognitive theory}

Edited by $G$ Eysenbach; submitted 15.03.19; peer-reviewed by S Chancellor, G Petrič, S Atanasova; comments to author 24.09.19;
revised version received 24.12.19; accepted 26.02.20; published 08.06 .20
Please cite as:
Liu Y, Yin Z
Understanding Weight Loss via Online Discussions: Content Analysis of Reddit Posts Using Topic Modeling and Word Clustering
Techniques
J Med Internet Res 2020;22(6):e13745
URL: $\underline{\text { https://www.jmir.org/2020/6/e13745 }}$
doi: $\underline{10.2196 / 13745}$
PMID: $\underline{32510460}$

(C) Yang Liu, Zhijun Yin. Originally published in the Journal of Medical Internet Research (http://www.jmir.org), 08.06.2020. This is an open-access article distributed under the terms of the Creative Commons Attribution License (https://creativecommons.org/licenses/by/4.0/), which permits unrestricted use, distribution, and reproduction in any medium, provided the original work, first published in the Journal of Medical Internet Research, is properly cited. The complete bibliographic information, a link to the original publication on http://www.jmir.org/, as well as this copyright and license information must be included. 